\title{
Climate Change Adaptation Pathways in Kolkata
}

\author{
Priya Parasuram*, Priya Narayanan ${ }^{*, \dagger}$, , Mark Pelling*, William Solecki ${ }^{\S}$, \\ Purvaja Ramachandran* and Ramesh Ramachandran* \\ *National Center for Sustainable Coastal Management, \\ Anna University Campus, Chennai - 600025, India \\ †Tamil Nadu Biodiversity Board, TBGP Campus, II Floor, \\ Velachery - Tambaram Main Road, Nanmangalam, \\ Medavakam Post, Chennai - 600100, India \\ tKing's College London, London WC2R 2LS, UK

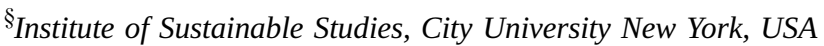 \\ Ipriyarika@gmail.com
}

Published 7 April 2017

\begin{abstract}
Disaster risk management and wider processes of adaptation are too often understood in isolation from development. Kolkata faces increasing heatwaves, flood hazard and everyday waterlogging as a result of climate change but the social and spatial distribution of impacts will likely be mediated by historic and contemporary development decisions. The paper reports on a study that has combined a scenario workshop method and expert interviews to surface the views of risk and resilience planners, academics and urban professionals on the adaptation-development nexus. Kolkata is experiencing rapid and fundamental transition in its governance regimes and economic structures as state-led development gives way to stronger market forces. Planners welcome an opening of urban governance but are worried by the speed of change. Transition in risk governance is observed in a predicted shift from a contemporary orientation where capacity is limited but focused on protecting development gains, to one which also embraces the flexibility of resilience.
\end{abstract}

Keywords: Adaptation; development; risk management; transition; Kolkata.

\section{Introduction}

In the constantly changing urban environment, both human and natural factors create risk in cities which need to be mitigated, prepared for and responded to as

This is an Open Access article published by World Scientific Publishing Company. It is distributed under the terms of the Creative Commons Attribution 4.0 (CC-BY) License. Further distribution of this work is permitted, provided the original work is properly cited. 
part of ongoing development struggles (Pelling 2003). Urbanization, as a global phenomenon, is also increasingly coastal. In India, Kolkata is part of this trend. The capital city of the Indian state of West Bengal, Kolkata is prone to flooding during moderate to heavy rainfall owing to its relatively flat terrain and tidedominated drainage outfalls. A joint occurrence of high tide and high rainfall can bring the city to a standstill, as occurred in 1978, 1999 and 2007 (Sen 2013). Kolkata has long confronted flooding and land drainage issues. In 1863, the city was the first in India to deploy an underground sewerage system at the city scale — at the time covering 19 square kilometers (Sen 2013). Today, much of the city's planned infrastructure has met its limits with a large informal population living without access to critical infrastructure. Swiss Re (2013) have rated Kolkata globally as the city with the seventh highest population at risk from natural hazard events with 17.9 million exposed residents. Looking ahead, Kolkata is experiencing slower population growth rates than other cities in India, though demographic pressures remain high (Yadav and Bhagat 2016). In this context, adaptation to climate change in Kolkata is a complex process involving integration of policy and practice at multiple levels and with a dynamic development and risk context.

Who is involved with adaptation decision-making will determine what is seen as important in the city and so which assets are prioritized for protection and which are expendable or open to being adjusted under adaptation (Pelling 2009). Adaptation is inseparable from development, with the adaptation-development nexus expressed through efforts to protect, adjust or fundamentally change existing development processes, practices and outcomes as the intention of adaptation (Pelling 2011). It may be that different actors hold not only different views on what is to be prioritized but on the desired balance of the adaptation-development nexus. This paper seeks to explore the pathways through which Kolkata's adaptation regime has been negotiated between key actors and processes and how far these actors find the existing orientation able to deliver a sustainable and resilient city looking to mid-century.

Kolkata's mosaic of formal and informal land-use and the interdependencies of the formal and informal economies render a complex patchwork of risk and resilience across the city. In Kolkata, more than $60 \%$ of the economically active work in the informal sector, often working from home (Shaw 2016). Concentrated in the city's low-income districts, throughout the city and its satellite villages, the combination of informal home-working and poverty highlight the vulnerability of this population to flooding and waterlogging in low-income residential areas. Slum settlements exaggerate vulnerability combining informal economic activity with insecure land tenure and limited access to critical infrastructure. Working in Indira Palli Slum, Ward Number 80, Bhadra and Das (2016) describe the additional 
security challenges faced by women and children as their lives, livelihoods and homes are affected by hazard events. Following a disaster, emergency access was made difficult by narrow lanes (often also used for cooking and washing), public water points were at a distance from many homes and emergency workers were not always respectful of women and children's needs. Above all, Kolkata's mixed land-use and economic interconnections reveal the sensitivity planners need to take account of the flows of risk and resilience between land-uses and economic activities. Rumbach (2014) illustrates this through the case of Salt Lake City, a new town development that provides integrated planning solutions to manage flood risk inside the planned settlement, but does not extend this to the informal settlements that have arisen on adjoining land to service the formal economy of Salt Lake City. De facto, then informal settlements have been planned out of the risk management regime for the city. In both the Indira Palli Slum and Salt Lake City, dominant development practices and in particular, challenges limiting scope for integrated development have built risk into the urban fabric.

Cities are centers of economic growth, with the imperative for adaptation to climate change opening scope to reconsider development choices (ADB 2015). The Kolkata Metropolitan Corporation (KMC) is responsible for managing adaptation and mitigation in the city and is currently developing a roadmap for this. The State Action Plan for Climate Change (SAPCC) highlights the criticality of Kolkata as a region prone to flooding during cyclonic storm surges. Risk is understood in terms of inadequate infrastructure, land-use, socio-economic and environmental conditions, and the drainage capacity of the existing sewerage systems. A predominantly physicalist orientation leading to the prioritizing of engineering solutions to risk socio-economic determinants of vulnerability are identified, but the report falls short of identifying root causes of vulnerability and infrastructural inadequacies in the economic and political models of Kolkata's development pathway.

The KMC is empowered under the 74th Constitution Amendment Act (CAA), June, 1993, which sought to strengthen decentralization in support of urban local bodies (Draft Strategic Plan of Ministry of Urban Development, 2011-2016). At the national level, the Ministry of Urban Development (MoUD) has initiated multiple schemes to develop cities with basic amenities and also strengthen cities to be resilient to climate change. At the city level in Kolkata, a systematic strategy towards a better city structure involving stakeholders across different sectors (academic, government and non-government) focusing on investment mobilization, planning, grievance redressal mechanisms, heat and health action plan, data and information needs, early warning systems and manpower needs has been prepared.

This paper examines the preparedness of KMC to adapt to future hazard and vulnerability in the context of climate change. The scope of the study is to observe 
the drivers, challenges and opportunities for risk management in Kolkata's current and possible future regimes. Here, the risk management regime is defined as an established set of institutions, norms and behaviors that dominate a pattern of promoting risk management, wherein a set of assumptions and assertions concerning the conceptualization of risk and the roles and responsibilities of various governance structures are embedded (Solecki et al. 2017). In particular, our study distinguishes four regime states based on their stated intentions: (1) to provide stability for planning and business so that development is not interrupted by risks or risk management (resistance), (2) to help planners and business undertake marginal change in activities in order to avoid major losses (resilience), (3) to address inadequacies in current planning and business practices that are the root causes of risk (transformation) and (4) to have no strategic policy, where any activity is highly fragmented and uncoordinated (collapse).

With this framework, the study seeks to identify the current risk management regime and scope for transition within the range of regimes described above by asking the following questions:

(1) What is the current city risk management regime and which processes and actors have been dominant in establishing this state?

(2) Is there desire and scope for transitioning to new disaster risk management regime orientation?

(3) What constraints and barriers constrain transition?

The following section outlines the research design and methods. Subsequently, the paper presents and discusses key findings and in conclusion, examines the scope of transition in risk management for climate change adaptation in Kolkata.

\section{Research Design and Methods}

To identify regime status and transition pathways in the city, two types of participatory methods were used: a scenario workshop and expert Interviews. This research design was used uniformly across five cities (Kolkata, Lagos, London, New York and Tokyo) as part of a systematic analysis of risk transition in these global megacities (see www.bel-truc.org). Table 1 shows the broad spectrum of experts and practitioners who participated in the study.

The scenario workshop was conducted in February 2015 and aimed to understand the perception of stakeholders on the city's adaptation and development pathways, and their interaction. Semi-structured interviews were used to get a better understanding of the management of disaster risk in Kolkata. Individuals from a variety of disaster risk reduction sectors were interviewed. Interviews were 
Table 1. The List of Experts and Practitioners

\begin{tabular}{lcc}
\hline Sl. No. & Category/Sector & Number \\
\hline 1 & National Government & 3 \\
2 & State Government & 4 \\
3 & CitGovernment/Municipality & 1 \\
4 & Business/Private & 3 \\
5 & Academics & 5 \\
6 & Civil Society & 4 \\
\hline
\end{tabular}

based on one-on-one interaction or remote communication via telephone or email. The duration of each interview was 45-90 mins. The interviews were held between January-July 2016. Access to KMC officials was restricted so that other stakeholder groups were disproportionately represented in the interviews and workshops (see Table 1). The semi-structured questionnaire was divided into three sections addressing risk management regimes and priorities, capacity and trajectory for transition and future risk management strategies in KMC. Experts provided their viewpoints on development, implementation and control of strategies and policies related to climate change and its associated risks in Kolkata.

Using these two methods helped participants to debate, discuss, reflect and voice their opinions on the status, pathways, drivers of transition and the means or practices that need to be employed in future for shaping the adaptation-development nexus in Kolkata.

\section{Results}

\subsection{The dominant risk management regime and its drivers}

Risk management in Kolkata is largely inclined towards disaster response. The expert survey respondents and participants from the scenario workshop shared the opinion that it would be extremely difficult to build a long-term, coherent strategy for risk management in the city. This was because of the influence of political party control on policy priorities, including risk management. Political party influence is felt at the level of policy formation but also at the point of implementation with long time periods between these two allowing political interpretation and capture which is felt especially at the local level. As one respondent reported the result is a fragmented and low-priority risk management regime:

"Political agendas and priorities keep changing, public awareness towards existing risk management framework and strategies is very minimal; general public largely do not participate in most decisions that revolves around their own well-being” 


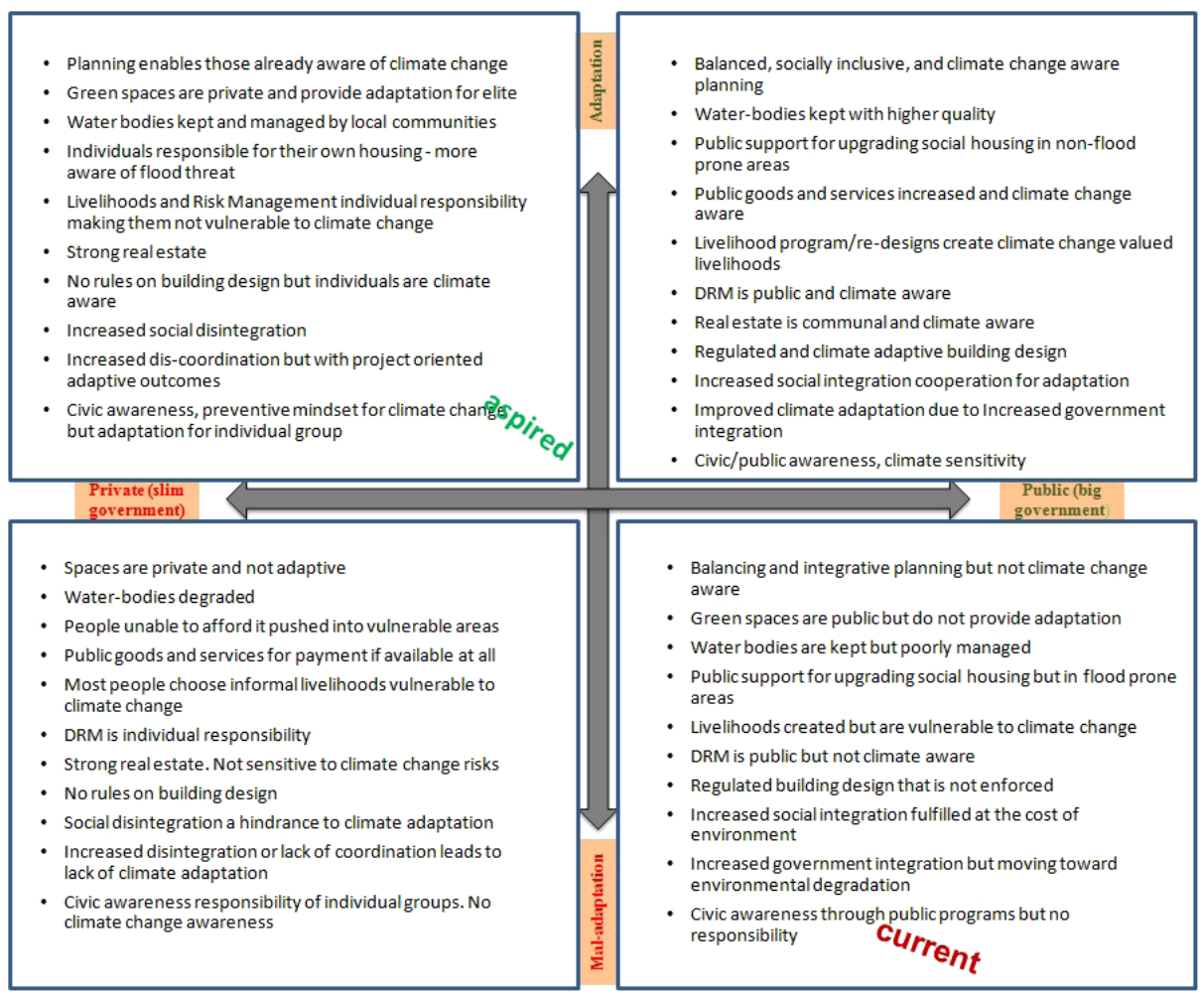

Figure 1. Climate Change Adaptation and Development Scenario for Kolkata

Figure 1 summarizes the viewpoints of stakeholders present at the scenario workshop. The figure shows two axes, four resulting scenarios and their components. With the exception of the adaptation-mal-adaptation axes, these were all generated by stakeholders. The second axis was developed based on participant views on the fundamental development trend experienced by the city, described as a shift from public to private sector-led development. Of the resulting four scenario spaces, current status was described as public sector-led development, but with strong mal-adaptation (bottom right quadrant). This was considered as a regime that lacked integration across departments for effective management of public infrastructure, lacked law enforcement for proper enforcement of building regulations and that climate change was not fully accepted as a priority leading to a lack of responsibility by authorities when it came to managing resources and risks. Respondents were asked to describe their desired future state, and described this as a balanced economy with a small lean towards private sector-led development and adaptation, but without an aggressive push for adaptation (the top left 
quadrant). This would be characterized by project-oriented adaptive outcomes, increased responsibility at the individual level and local community-based management of resources and risks. This would also include an enhanced city planning infrastructure and overall more focus on individual awareness about climate change.

Interviews supported this view and identified the importance of the KMC for coordinating urban development. This involved management of housing, water bodies, green spaces and disaster risk. However, the capacity of the respondents of the KMC was limited and open to political influence, for example, through individual political leaders intervening in the distribution of services to individual city districts. This concern led participants to wish for a transition towards a more mixed governance approach that could enable local community-based risk management and individual responsibility for resilience building. The transition from a strong city government led model towards a more mixed or even private sector led model for urban development was already underway and respondents expressed a process of rapid current transition that left many worried about the speed of change despite a general agreement with the direction of change. This contemporary transition in the model of development in the city will have a profound effect on the adaptation-development nexus through risk accumulation and management processes. Any adjustment risk management voice made on the prevailing, rapid economic transition is likely to be marginal. Risk management is not a priority area and integrating this into development planning, and especially having any impact on development planning priorities is unlikely in the short-medium term. City level politicians were reported as being very focused on key sectorial concerns, promising to provide basic services so that larger-integrated policy areas like integrated climate change risk management, though debated, were not fully considered in KMC planning discussions. While academic institutions have produced conceptual and analytical work to understand risk management in the city they had not been wellconnected to the public discourse. National level influence was felt but this was focused on notions of the 'smart city', using technology to facilitate informationbased service delivery and not on more fundamental reforms of the adaptationdevelopment nexus.

The importance of city political party interests in shaping policy directions was confirmed through expert interviews (Figure 2). Here, respondents complained that parties were not responsive to the electorate which was organized around block voting and clientelistic relationships in many constituencies. Economic inequality emerged as the next most influential factor. Popular priorities were very low as a 
P Parasuram et al.

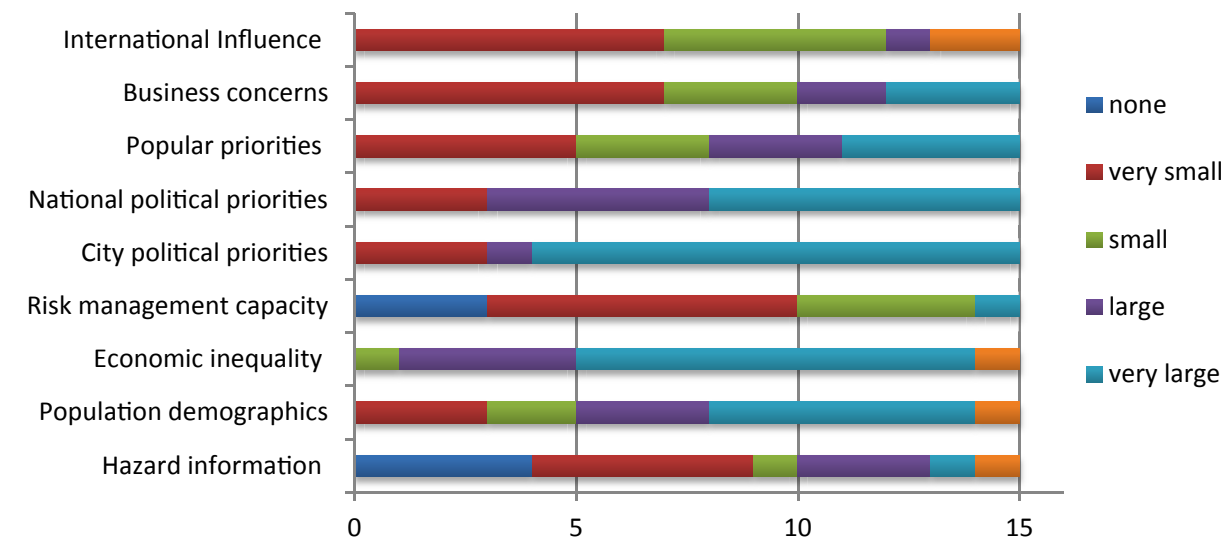

Figure 2. Factors Influencing the Current Adaptation Pathways

driver of city policy reflecting a regime that shuts out popular discourse. One respondent commented that

"The absence of transparency and advertising in government prioritising and policy, decision making has resulted in lack of awareness among general public."

It is to be noted that the KMC has a dedicated Climate Change Cell (a multidisciplinary program for climate resilience) which has issued a Road Map for a Low Carbon and Climate Resilient Kolkata (Kolkata Climate Change Cell 2015). However, awareness about this is very minimal. A respondent from the KMC explained that

"Integration and information exchange between departments is still quite constrained leading to issues in dissemination of information.”

A majority of the respondents also considered that the role of international organizations and private business concerns in defining the city risk management regime was very small. They attributed this to the socio-political structures that existed in the city being unattractive for new investments and robust in the face of external development conditionalities. However, it was noted that the city was moving towards becoming a more business and investment-friendly environment as part of it shift towards a private sector-led economy. At the national level, specific agendas have been outlined for making cities a better place to live and also incorporating resilience as a component of this. The Atal Mission for Rejuvenation and Urban Transformation (AMRUT) (see http://amrut.gov.in/), includes an incremental process of achieving Service Level Benchmarks for various amenities to 


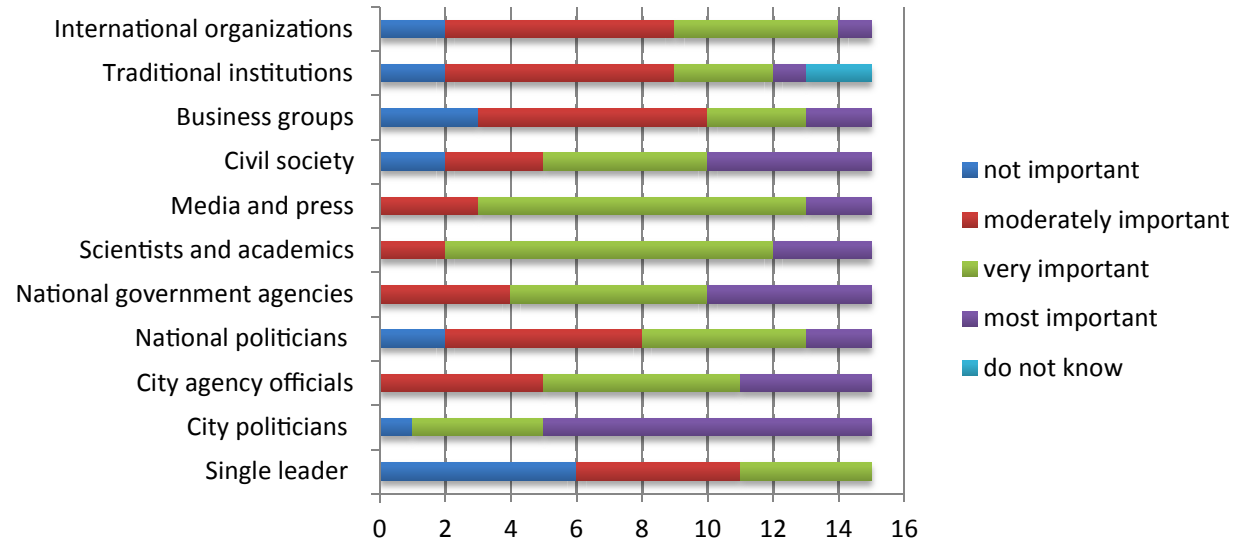

Figure 3. Factors Currently Influencing Adaptation

help make cities resilient. The idea of AMRUT is to help cities transition to a better managed city space. However, the absence of transparency in the application of national government schemes, accompanied by lack of inter- and intradepartmental integration in Kolkata has pushed the city's risk management regime towards a state of resistance and away from resilience.

Figure 3 indicates respondent views on the relative importance of different actor types in shaping the contemporary risk management regime and its orientation towards development. City politicians were reported as being by far the most important actors. City agency officials, national government agencies and civil society represented a secondary tier of influence with scientists and academics. An urban planner commented on the over-riding influence of urban politics:

"If the representatives of the majority party in the state are elected as councilor in the city wards then relatively efficient functioning and management of common property resources, etc. takes place. However, if the ward representative or councilor is from a different political party then difficulties arise at multiple levels from dissemination of funds, information, etc."

For the majority of the respondents, the role of international organizations, traditional institutions and business groups was quite marginal to city policy making. An academic noted that the role of non-governmental organizations was limited to raising the public visibility of current social and ecological issues:

"The role of the non-governmental institutions is mostly confined to voicing issues but an effort towards collective, action-oriented mechanism for resolving issues is very limited." 
That the contemporary adaptation-development nexus was a dynamic one was highlighted by a respondent from the private sector. She held the view that the private sector was now heavily involved in investing for critical service provision - moving from real estate investment into health, education and communications. It was argued that while this has opened capital investment, the trend had no proper or sustainable development interests at its core. Beyond replacing a centralized city government with corporate private capital, the respondent felt there was a desire to move the regime towards greater local accountability, indicating a desire for transition towards a more transformative orientation in risk management (see Section 3.2):

"A regime shift in the ideation of risk management strategies towards a more local, people centric and systematic approach."

A representative from the State government department explained that while a single leader may be able to attract votes, in government, decision-making was decentralized. There were no cases of charismatic KMC leaders pushing through policy directions in the establishing of the current regime.

"A single leader can only be influential, but only in attracting people towards electing him to be a representative, but when it comes to getting work done it is not always single person's responsibility. There is a chain of command in this process which has many irregularities."

\subsection{Desire and scope for transition to a new disaster risk management regime orientation}

In assessing the drivers and constraints on Kolkata's resilience regime, it is to be noted that growing inequality between households will likely have a great impact on the effectiveness of risk management (Rumbach 2014). An academic explained that

"Access to basic needs and protection during any disastrous event is very income-specific! The rich have more accessibility and insurance towards life and property whereas the lower income groups are not fully covered."

Existing vicious cycles between poverty and risk in cities can be challenged. There is scope for Kolkata to learn from other cities in India and elsewhere, where measures have been taken to build more inclusive decision-making that is sensitive to the limitations of existing policy-making (Corfee-Morlot et al. 2011). There is 
now a strong body of evidence that finds inclusive social processes, especially, those articulated through networks of community organizations connected to local government open new space for accountable policy-making and project implementation that can reduce risk and enhance local stakeholders' participation in urban processes (Satterthwaite and Mitlin 2014).

Kolkata's physical infrastructure is aged, fragmented, often fragile and not well suited to coping with additional stress associated with climate change. Reorienting the city and its management to build resilience and tackle unmet development challenges will not be easy. There are though informative antecedents. The historic one house, one pond 'pukur' system (http:hriindia.in) provides a cultural starting point for local self-responsibility and one that was historically bound up in supportive, if hierarchical, social ties and obligations. Pukur might provide a culturally-specific way of communicating the advantages of self-responsibility in water storage and drainage in some parts of the city. For policy, in general, it is weaknesses in the supportive social ties needed to build a political citizens groups connected to local government that is perhaps the greatest challenge for integrating risk management and progressive development going forward.

One civil society respondent noted that Kolkata's constraint lay in being an over-exploited and over-populated mega-city in which following the goals of sustainable development were not easy. Regardless of awareness among the citizens, participation towards making a city resilient was low:

"Collective responsibility is missing, people are always receiving information but not participating in designing any effective mechanism for a city to grow and sustain."

Recent incidents including fire, building and flyover collapse acted as drivers for remodeling the city's risk management regimes. For example, the West Bengal Municipal Building Rules 2007, regulate building in the municipal area, industrial area and townships. However, there is a need for more stringent enforcement of these rules, regular evaluation and monitoring. An urban planner from the Kolkata Metropolitan Development Authority highlighted the need for regulation, referring to recurring fire incidents in buildings in Kolkata. Improper management of space by both public and private constructors, lack of evacuation drills and lack of welltrained staff are a few of the constraints cited as obstacles for the city to realize even its current risk management regime.

"We had three major accidents in Kolkata sometime last year and a flyover collapse early this year, but however, no strategy is followed when such events occur and we are always in a fire fighting mode." 
Expert interview respondents were offered four scenarios to open discussion on the thresholds around which current risk management policy would require fundamental change. The scenarios presented simple and cumulative risk stories (and were presented in each city study site):

- Scenario A: A doubling of rainfall and heatwave hazard.

- Scenario B: A doubling of rainfall and heatwave hazard plus a doubling of the population over 65 years of age.

- Scenario C: A doubling of hazard of the aged population and of the population below the city poverty line.

- Scenario D: A doubling of hazard of the aged population of the urban poor population and halving of risk management capacity.

Reflecting on each of the scenarios, a government agency project leader highlighted the need for fundamental change in the functioning of urban governance if any intentional transitions were to be realistic.

"Regardless of the changing political agendas, the scenarios will need a major uphaul, rather fundamental change is essential at multiple levels."

This was echoed by the majority of respondents who commented on the need for substantial and focused effort for any meaningful, deliberate transition in the governance of development and risk in the city. The majority of respondents explained that the existing risk management regime was inadequate to cope with any of the future risk scenarios. For any strategic transition to be considered, a prerequisite would be invested in human capacity and reformation of the internal processes of governance. An academic reported that:

"A well prepared and active disaster management department is needed to deal with the current and future risks of Kolkata city. Proper training and funding from Government departments would be needed to implement the national policies and legal framework."

An urban planner expressed a similar view, that the need for transition was clear and indeed that increasing vulnerability and losses were less persuasive as a cause for future transition than the need to invest in capacity:

"Aging population would never be an issue in India. So that, it's never going to pose as a risk factor for the future development. The immediate requirements are technical development, 
wide-scale actions from all the levels of Government and availability and sharing of funds among agriculture, business and service sectors."

In addition to low technical capacity, ongoing political prioritization was reported to hinder policy coherence and undermine programming for resilience through preventing the breaking of vicious cycles of risk production. A social worker from Kolkata explained that:

"The priorities of state government that itself are relatively new due to shift in power are confusing at best and absent at worst. If one looks at the city and the state and its conditions, then nothing much has changed and further deterioration fueled by the market demands has continued (marsh land have been filled up for buildings, parks and open spaces have disappeared rapidly etc.). Other future elements would include massive health problems due to environmental issues caused by humans, which will in turn aggravate poverty in the city and the State. This will lead to increase in crime, including human trafficking, and also force people to mass migrate to other states (both of these are already very high)."

Presented with these four scenarios, respondents stated that there was no strategic risk management regime prevailing in Kolkata and that any future risk scenarios would include major social concerns around poverty, migration and health problems potentially leading to social and economic instability. A senior policy advisor noted that

\begin{abstract}
"Management of drainage systems and other local level safety measure are the starting point for risk management. If a disaster happens, we can compute damages on income and property but during the disaster phase, the relocation help from neighbors, etc. cannot be really valued in money terms. But in a normal scenario, also for a city to run well, based on economic benchmarks, the deserving should get things in a subsidized rate. The rich people should pay more tax and poor should be able to get the basic amenities."
\end{abstract}

Among all four options (Scenarios A-D), respondents unanimously repeated the need for major changes in the risk management approach to maintain an acceptable level of risk. In this context, it is unnerving that respondents identified 
Scenario D (more heatwave, flood hazard, an aging population, more poverty and diminished risk management capacity) as the most likely future scenario for Kolkata city.

A government policy advisor suggested major changes would be needed to current risk management strategies to face future natural and other hazards

\begin{abstract}
"The current policies and Government schemes are not enough to manage the future risks. The most important to remember is, sustainability of resources. Optimum use of resources are the only way to achieve sustainable development. Government schemes are not always promoting sustainable use and if we do not promote it, at least by now risks will be at maximum, and no policies would be helpful to recover from that."
\end{abstract}

The chronic shortage of expertise in government and the need to reform communication between levels of government if risk is to be better managed was flagged by a government administrator:

"Change in attitude towards the problems is the immediate need.

Rising inequality in all levels of administration is an emerging challenge for policy makers."

Figure 4 summarizes the views of respondents when asked to describe the current and expected future risk management regime. The future regime being imagined in 20 years' time, by 2035. A bifurcated current regime has equal elements of collapse (no capacity for strategic planning) and resistance (risk management's function is to protect existing economic development priorities). Future risk management strongly moves towards resilience with continuing elements of collapse and resistance. Transformation (development targeted as a root cause of risk) is largely absent from current and likely future risk management regime descriptions. While the anticipated transition towards resilience is welcomed and will bring more long-term stability to infrastructure in the city on the back of national
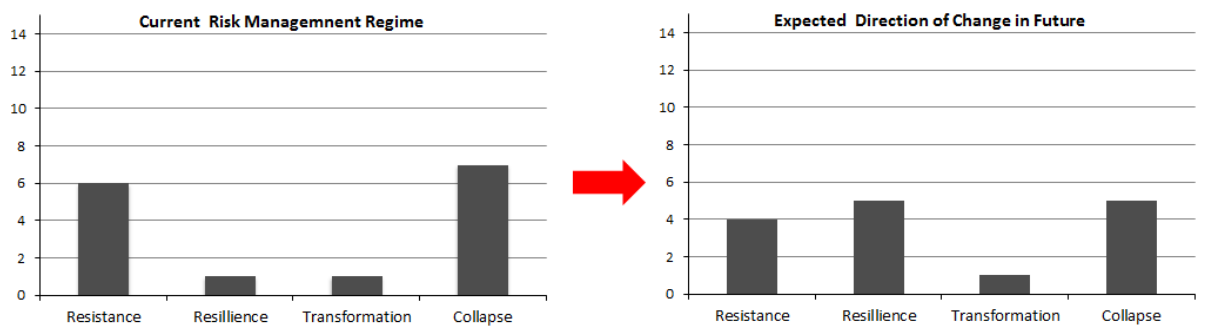

Figure 4. Expected Direction of Change in Risk Management 
resilience policy and city level pro-business development, the continuing presence of collapse and absence of transformation are concerning. That collapse persists reinforces the viewpoints of individual respondents who have described the depth of challenges required to enact existing let alone desired future risk management aims. The absence of transformation in a context where fundamental changes in development priorities and pathways are perhaps the only way to sustainably reduce risk indicates the intractable quality of existing governance structures in Kolkata.

A stakeholder from the private sector explained how the political priorities are a constraint on people-centered risk management

"The risk management strategy of India depends on many different things. Many strategies are started to manage risks but not much effective. The ultimate reason would be shifts in political agenda, where security of people comes as the last option."

A social worker starkly reinforced this view identifying how those at risk were also unable to challenge dominant policy structures:

"The political will for change towards protecting the environment and strategic risk management is missing. People are also too compliant and would rather die, migrate to other states or get into the viciousness of human trafficking than stand up and demand from those in power. All these factors have led to a situation where there is complete and blatant neglect and no strategic risk management plan"

Respondents considered that future transition in risk management regimes depended on breaking these constraints and on building better cooperation between administrators and people. Many commented on the need to build improved information flow between stakeholders and also among sectors to help achieve this. The KMC seems to recognize these challenges. The KMC Roadmap for Low Carbon Resilient Kolkata (2015) identified important components for transition to a better managed regime as: transparency, technology and awareness. The plan emphasizes the need for integrated planning, communication and decision-making (described as multi-dimensional, multi-sectoral and cross-cutting) if these components of a resilient city are to be built up. An academic described some moments where citizen action has itself pressurized government towards increased local accountability in risk management:

"Yes, under certain conditions of pressing need and demands of people from the government authority, the aim for risk reduction 
policy is changing in Kolkata. People of Kolkata have become more aware and more sensitive to the decisions of authority regarding risk management. This has brought about changes in responsibility of the state authority because now they know that they are directly answerable to people regarding whatever they do for risk reduction/management."

A parallel survey of household views (Narayanan et al. 2017) found that accessibility to information on Kolkata's climate change risk management plans was a first step in supporting local resilience building, but that for many households awareness on its own did not lead to behavior change. Citizens involved in brainstorming sessions to explain their needs and requirements for creating policies were more likely to engage in community resilience building. Indeed, as one social worked explained, information on its own can generate inequalities in local risk management capacity:

"Most of the time, people will come to know the existence of disaster management plan after the disaster. Before the next disaster either they will forget it. Technical accessibility is not equal for all, who all are having access may not be the needful. Government should plan campaigns and other easy informative methods to reach to people. Publishing in website or applications on phone will not be helpful in practical situation. If we start now at least by 2035 half of the population will be benefitted."

\subsection{Capacity and trajectory for transition}

In shaping the current direction of change in Kolkata, it was evident that city-level political leaders played the lead role in delineating trajectories for strategic city level management. However, apart from local political leaders and groups, media and the scientific and academic community were also identified as crucial actors (Figure 3). Nevertheless, constraints at multiple levels (decision-making, financial and resource availability) have forced stakeholders to choose for a complete change in current planning and practices. An academic pointed out that the present risk reduction policy in Kolkata city was already achieving some movement towards resilience it provided a framework to help planers and businesses learn how to accept some impacts of hazard risk in order to avoid major losses. According to her:

"Yes, under certain conditions of pressing need and demands of people from the government, the aim for risk reduction policy is 
changing in Kolkata. People of Kolkata have become more aware and more sensitive to the decisions of authority regarding risk management. This has brought about changes in responsibility of the state authority because now they know that they are directly answerable to the people regarding whatever they do for risk reduction or management"

Notwithstanding such indicators of citizen engagement, the confrontational and agitational socio-political landscape in Indian cities, including Kolkata, tends to force risk management regimes into a reactive mode. City leadership is wary of the professional risks that come with innovation in a cultural environment charged with urban politics. A civil society member attributed the lack of trust between city stakeholders through an absence of evidence-based planning and a seeming distance between policy makers and those on the ground who witness and experience the consequences of policy:

"There is no evidence or examples to prove if a particular strategy functions well, so there is lack of trust in the system! Policy makers themselves are far away from the plans and strategies they create, so if a major event happens lessons are not always learnt and we do not seem to improve our risk management methods."

At the national and state level plans to move towards more sustainable development pathways could set a framework to move beyond city level political positioning. However, an actor from the private sector emphasized that any progressive change in city level planning, state and national level planning is really very hard to anticipate, since political agendas and priorities always dominate this process.

"I do not expect any change at all in the years to come, though definitely population pressure, crunch in employment opportunities, scarcity of natural resources, increase land price, rising temperature and erratic rainfall etc., are being experienced in this city; I see no definitive steps for future. I still feel if a major disaster happens we would struggle in the present and in the future."

The tension between desired transition towards resilience based on increased connectivity between government and local actors, and the observed transition 
towards more business dominated but resilient development was captured well by an urban development advisor who remarked that:

"KMC's transition definitely would depend strongly on knowledge sharing between residents, authorities of ULB's (neighboring jurisdiction) and authorities from the judicial systems. KMC's landscape also right now is defined and ruled by real estate builders who tend to dominate political arena too! Urban environment is being altered quite drastically. Further I see no appropriate prioritization on urban transport and housing rules and regulations. Lack in coordination between different government agencies and distrust among public, class based politics etc., makes transition and sustenance towards complete resilience a very difficult scenario."

A view from civil society described the instability of the current risk management context which made transition towards resilience difficult:

"All systems are very unstable at this moment. First, aim is to have a stable condition for all people that is an actual effective trained and prompt disaster management cell."

At the neighborhood level, block voting and clientelism not only limited local capacity for transition but influenced the culture and practice of city level planning making evidence based, strategic planning difficult (Chatterji and Roy 2016).

The road map for climate change provides a platform to integrate the different stakeholders with an interest in urban climate resilience issues. The importance of such top - down plans in the Kolkata case were supported by stakeholder views that identify administrative structures as the most important driver for transition (Figure 5). An academic from Kolkata explained that:

"People who are in state and city Government and elected representatives at city level should act when the country needs them. It was also elaborated that the administrators are the most powerful and significant actors, who will reshape the present and future risk management regimes."

Contextual factors (development and economic change) and science and technology were important secondary factors with public values also being important in the view of stakeholders. 


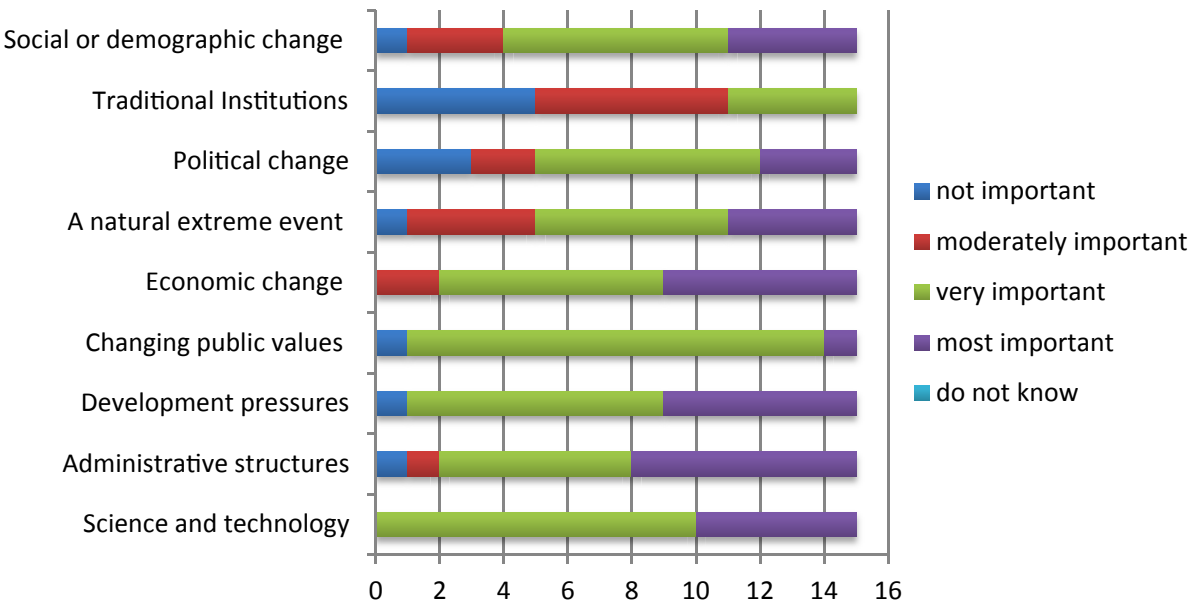

Figure 5. Drivers for Policy Transition in Kolkata

\subsubsection{Barriers in transition towards a more transformative regime}

A transformative regime is one that would target fundamental development processes and practices and recognize their role in producing vulnerability and risk. This is a challenging agenda for development and risk managers. In Kolkata, as discussed above, administrative and cultural contexts make such an agenda even more difficult to realize. Kolkata's political-administrative system makes strong singular leadership difficult and at the same time division across party lines on all agendas is an important barrier that disrupts scope for strategic transition towards a transformative regime.

A representative from the State Department of Welfare further highlighted the depth of clientelism and politicization and the role of caste-based identity in this. Caste politics were identified as a tension making it very difficult to initiate and maintain proper civil society networks of sufficient scale to engage in strategic city level action.

"Caste still plays an important role and is also used as a tool for
vote bank by politicians, so planning for a community at large
scale becomes increasingly difficult, because even during a
disaster one group is chosen above the other."

A key proximate driver was identified in the city's booming real estate industry. Inadequate regulation of urban speculation and development has led to increasingly haphazard land-use in the built-up urban environment and a multiplying of hazards. The East Kolkata Wetlands, which earlier played an important role in 
maintaining ecological balance is now under severe stress from development activities. However, the current risk management regime has little or no influence for capturing such exploitative development acts. An authority working with the disaster management department commented that:

"Ground water extraction and increasing levels of arsenic and its associated pollution are also a very important issue that need to be included in formulating any risk management policies in future."

A senior government advisor from Kolkata indicated that benefits in climate finance were not always very attractive though India has a large potential to attract such funds. According to him:

"Natural resource is abundant and market for resources is untapped, hence investment on that is not very alluring. It is also difficult to convince people since the people invested in climate adaptation and the people benefited from climate finance are not always the same."

An academic also explained the contradiction in Kolkata of a city in a state with relatively high levels of education yet with limited representation of women in many lead roles and limited technological innovation. The respondent felt there was a tendency for people to be disengaged from public action and not be proactive, though they were informed. The low level of public engagement including women's participation and limited technological innovation was indicative of difficulties for the city manager and officials wishing to see popular voices push for reform or a change in direction of policy.

"Not often education and role of women go hand in hand, and historically, we have not really entertained change in any kind of development so easily, we have always resisted to change, making moving forward a sluggish affair."

To summarize, interviews indicated scope for transition from resistance and collapse towards resilience. Respondents were positive that in the near future, widening of adaptation pathways which includes better governance, infrastructure and a positive investment environment could put Kolkata in a regime which would be more resilient and sustainable. However, this would only be possible if national policies like SMART cities, AMRUT and SWACH Bharat incorporated features to encourage city transition. 


\section{Conclusion}

The current administrative and political-cultural contexts of Kolkata have hampered integrated planning and tended to perpetuate the influence of clientelistic and political party-based alliances on policy formation. The deep-rootedness of these structures makes any future transition difficult while they persist. At the same time, Kolkata is undergoing rapid opening up of its economy to private sector-led development. This produces a transitional dynamics driven by the private sector that accepts the need for resilience, but not fundamental change.

During the course of our interaction with experts, it was evident that climate adaptation is an important agenda for city and state level planning. In the current regime, flood risk is managed in a responsive mode through the deployment of pumps to drain water immediately after heavy rains. Efforts to undertake proactive risk reduction, and risk management efforts targeting root causes in land-use, building design and infrastructure provision have not been successful. Transition towards this more transformatory mode of risk management was also difficult and respondents felt unlikely in the coming decades, despite its clear material need.

\section{Acknowledgement}

The report in this paper was undertaken as part of the Belmont Forum funded Transformation and Resilience on Urban Coasts (TRUC) project. This project was supported by Japan Society for the Promotion of Science, the UK Natural Environment Research Council and Economic and Social Research Council (NE/ L008971/1) the German Research Foundation (GZ: B1 1655/1-1). The Ministry of Earth Sciences, Government of India (MoES/01-CZM/Truc/2013), US National Science Foundation (ICER-1342966) and Social Science and Humanities Research Council, Canada (756-2014-0294).

\section{References}

ADB (2015). Asia's Booming Cities Most at Risk from Climate Change. https://www.adb. org/news/features/asias-booming-cities-most-risk-climate-change [May 6, 2015].

Bhadra, D and Das D (2016). Integrating gender sensitive approach in to disaster management - a case study of Kolkata slum. International Journal of Humanities and Social Science Invention, 5: 52-56.

Chatterji, T and Roy S (2016). From margin to mainstream: Informal street vendors and local politics in Kolkata, India. Online Journal of Political Geography and Geopolitics, 29: 1-19.

Corfee-Morlot, J, Cochran I, Hallegatte S and Teasdale P-J (2011). Multilevel risk governance and urban adaptation policy. Climatic Change, 104: 169-197. 
P Parasuram et al.

Kolkata Climate Change Cell (2015). Roadmap for low carbon climate resilient Kolkata. Kolkata: Kolkata Municiapal Corporation. http://www.kmcclimate.org/assets/doc/ Roadmap.pdf. Accessed on February 20, 2016.

Narayanan, P (2017). Adaptation transitions in Kolkata. Journal of Extreme Events in press.

Pelling, M (2003). The Vulnerability of Cities; Natural Disasters and Social Resilience. London: Earthscan.

Pelling, M (2009). Urbanization, human security and disaster risk in Africa. In Pelling, M and Wisner B (eds.) Disaster Risk Reduction: Cases from Urban Africa. London: Earthscan, pp. 3-16.

Pelling, M (2011). Adaptation to Climate Change: From Resilience to Transformation. London: Routledge.

Rumbach, A (2014). Do new towns increase disaster risk? Evidence from Kolkata, India. Habitat International, 43: 117-124.

Satterthwaite, D and Mitlin D (2014). Reducing Urban Poverty in the Global South. London: Routledge.

Sen, D (2013). Real-time rainfall monitoring and flood inundation forecasting for the city of Kolkata. ISH Journal of Hydraulic Engineering, 19: 137-144.

Shaw, A (2016). The informal sector in Kolkata metropolitan area: Appraisal and prospects for local economic development. In Dutt, AK (ed.) Spatial Diversity and Dynamics in Resources and Urban Development. Berlin: Springer Science, pp. 499-516.

Solecki, W, Pelling M and Garschagen M (2017). Urban risk management transitions. Ecology and Society.

Swiss Re (2013). Mind the Risk: A global ranking of cities at risk from global disasters. http://www.indiaenvironmentportal.org.in/files/file/Swiss_Re_Mind_the_risk.pdf. Accessed on September 2015.

Yadav, V and Bhagat, RB (2016). Spatial dynamics of population in Kolkata urban agglomeration. In Singh, RB (ed.) Urban Development Challenges, Risks and Resilience in Asian Mega Cities. New York: Springer, pp. 157-174. 